van Bühren/Lemcke/Jahnke (Hrsg.) Anwalts-Handbuch Verkehrsrecht 



\section{Anwalts-Handbuch Verkehrsrecht}

herausgegeben von

\section{RA Dr. Hubert van Bühren}

RA Hermann Lemcke

RA Jürgen Jahnke

bearbeitet von

RA Dr. Hubert van Bühren, Köln

RAin und Awocato Sabine Feller, LLM. (Master of Insurance Law),

München, Rom

RA Jürgen Jahnke, Münster

RAuNin Edith Kindermann/

RAuN Rembert Brieske†, Bremen

RA Herman Lemcke, VorsRiOLG a.D., Münster

RAin Karen Lessing, Hamburg/Köln

RA Klaus-Friedrich Meinecke, Münster

2. neu bearbeitete Auflage

2012

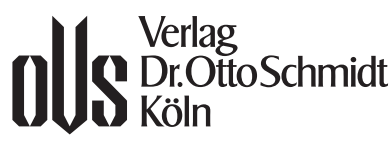




\section{Zitierempfehlung:}

Bearbeiter in van Bühren/Lemcke/Jahnke (Hrsg.), Anwalts-Handbuch Verkehrsrecht, 2. Aufl., Teil ..., Rz....

Bibliografische Information

der Deutschen Nationalbibliothek

Die Deutsche Nationalbibliothek verzeichnet diese Publikation in der Deutschen Nationalbibliografie; detaillierte bibliografische Daten sind im Internet über http://dnb.d-nb.de abrufbar.

Verlag Dr. Otto Schmidt KG

Gustav-Heinemann-Ufer 58, 50968 Köln

Tel. 0221 / $93738-01$, Fax 0221 / $93738-943$

info@otto-schmidt.de

www.otto-schmidt.de

ISBN 978-3-504-18060-7

C 2012 by Verlag Dr. Otto Schmidt KG, Köln

Das Werk einschließlich aller seiner Teile ist urheberrechtlich geschützt. Jede Verwertung, die nicht ausdrücklich vom Urheberrechtsgesetz zugelassen ist, bedarf der vorherigen Zustimmung des Verlages. Das gilt insbesondere für Vervielfältigungen, Bearbeitungen, Übersetzungen, Mikroverfilmungen und die Einspeicherung und Verarbeitung in elektronischen Systemen.

Das verwendete Papier ist aus chlorfrei gebleichten Rohstoffen hergestellt, holz- und säurefrei, alterungsbeständig und umweltfreundlich.

Einbandgestaltung: Jan P. Lichtenford, Mettmann Satz: Schäper, Bonn

Druck und Verarbeitung: Kösel, Krugzell

Printed in Germany 